budget earlier this year. He pointed out that the cases quoted by Mr Mattingly for example of consulting firms carrying out the same work for different agencies were several years old, and that with a tighter management structure and more narrowly defined missions, OTA was now beginning to demonstrate unique value to Congress.

Much to OTA's relief, Senator Mattingly did not take his case to the floor of the Senate, and OTA's 1982 budget is now secure. "I presume it did not come up because a lot of people on both sides of the aisle have come to see OTA as a useful and important analytical tool", said Dr Gibbons last week.

Much of the recent work, both long-term and short-term, has impressed OTA's congressional clients. "Some of their stuff is really excellent, particularly in the energy field" says one staff member of the House Science and Technology Committee. A recent report, Impacts of Applied Genetics, an analysis of the economic and commercial implications of genetic engineering applied to microorganisms, plants and animals, has been widely praised and recently reached the "top ten list" of government publications.

One secret of OTA's survival seems to be its greater awareness of the limits within which it can safely operate. The genetic engineering study, for example, avoided all discussion of the human apllications as "beyond its scope", and the MX study, while studying the "socio-economic" implications of the weapons' deployment, did not discuss political factors such as the full implications of local resistance. Dr Gibbons explains this pragmatically. "Our job is to narrow the issues that must be fought out rather than to tell the politicians what they should do", he says. He talks of breaking problems down into "bite-size" pieces, referring, for example, to recent OTA studies on energy utilization and demand.

Dr Gibbons is currently trying to forge closer links with the National Academy of Sciences, as well as discussing ways of complementing the policy orientations of the Office of Science and Technology Policy. Drawing technology assessment more closely into the traditional nexus of political decision-making may have disenchanted some of its earlier enthusiasts. But it has proved to be a formula for political survival. David Dickson

\section{Islamic science}

\section{Radicals agree}

Islam and a handful of radical Western scientists came together in a royal palace last week, leading to what one Islamic scholar called a "breakthrough in Islamic studies".

The objective of the meeting was to develop a critique of the role of science and technology in society as seen from an
Islamic perspective and using Islamic values. This is not a matter of counting Islamic angels on a needle point, but an issue central to the 42-riation Muslim world seeking both to absorb the fruits of science and technology without too much social disturbance, and to rally behind the flag and philosophy of Islam. The study was the first in a series of science in Islam and the West being organized by the International Federation of Institutes for Advanced Study (IFIAS), set up by the Nobel Foundation to consider issues of academic weight and world importance. King Gustav of Sweden has given the federation a palace as headquarters and conference centre.

Inspiration for the conference came from Ziauddin Sardar, a young Londoner born of Pakistani parents (and one-time correspondent of Nature) who has a passion for Islam and the issues of development in the Muslim world. He appears to have achieved a rapprochement between Westerners and the senior and devout Muslim scientists at the meeting.

Initially the meeting seemed likely to founder on the rock of the Muslim insistence on the purity of any search for knowledge. Islam directs the faithful to seek knowledge of the natural world, and inspiration in it: the world is the work of God. This concept, while appealing to Western scientific egos, seemed incomplete to the radicals - to whom some kinds of scientific knowledge were like a "second bite of the apple". This was heresy to the Muslims.

\section{Distinctive development}

The delicacy of politics in the Muslim world helps to explain why it has taken three years to install the director-general of the Islamic Foundation for Science, Technology and Development, Dr Ali Kettani, in the Jeddah headquarters.

Kettani has to deal with 42 diverse Muslim nations embracing Africa, the OPEC states and the Far East - each with its own internal political problems, its own approach to Islam and its own goal in "development". Kettani's goal is to forge an Islamic brotherhood of scientists and technologists, who would turn to each other, rather than to the West, to solve problems.

The foundation has been promised an initial $\$ 50$ million for $2-3$ years recommended by the Organization of the Islamic Conference (of which $\$ 15$ million has already been paid by Saudi Arabia). There is to be a staff of some $30-40$ and a charter which requires the foundation "to ensure that all member countries ...., both individually and collectively, make the greatest possible use of science and technology (including the social sciences) in the formulation and implementation of their socio-economic plans, keeping in mind the need to consolidate the unique Islamic personality and character".
The Westerners would also not allow a firm distinction between the search for knowledge and its use, which would have solved the dilemma. The idea was simplistic, they said: half the world's science is attributable to defence and industrial research budgets, even if that science is, in its minutiae, "fundamental".

The solution came from Dr Ali Kettani, recently appointed director of the Islamic Foundation for Science, Technology and Development (see box). In Islam, both the ends and means of an individual's actions must be "hallal" (allowed), so knowledge sought within a context of "harram" (forbidden) use would also be forbidden.

The social context and consequences of science could also be considered within Islam, the meeting judged, using precisely defined Quranic concepts such as "adl" (equity), "zulm" (oppression), "muslah" (public interest) and "dyah" (waste).

A measure of the success of the meeting was that the participants tore up their papers, prepared before the conference, and which were to have been the basis of a book, promising to rewrite them in the light of what they had learned. Subsequent meetings in the seminar series will turn to more practical technical issues, such as energy and environment (to be held in Riyadh), habitation, agriculture, health, and industry and mass production.

Robert Walgate

\section{London science centre} \section{No cash ahead}

The new London Science Centre is appealing for money to keep going for a second year. The centre was established last April by the Foundation for Science and Technology with about $£ 50,000$ of donations from learned societies and industry. It is now looking for a further $£ 200,000$ to tide it over until it becomes self-financing.

The centre's aim is to provide facilities for small learned societies whose existence is threatened by the high cost of central London. So far, interest has been modest. Only twenty-six societies have joined, and are entitled to pay less than the going rate for assistance with their day-to-day administration. The main facilities on offer are two small conference rooms and five offices, together with secretarial assistance, at the centre's rented headquarters in the Royal Society of Arts.

The centre's preoccupation during its first six months has been to take over the role of liason among learned societies from the Royal Society. But plans for the future are more ambitious. The idea is that the centre will not only of fer facilities such as word-processing and computerized membership lists, but will become a focus for interdisciplinary communication.

Even so, its centre is the residue of a far more ambitious scheme to emulate the Clunies Ross Memorial Foundation set up 